\title{
INFLUENCE OF THE MICROSTRUCTURE ON THE CREEP BEHAVIOUR OF TIN-SILVER- COPPER SOLDER
}

\author{
Pedro E. Ribeiro \\ School of Engineering \\ University of Minho \\ 4800-058 Guimarães, \\ Portugal \\ Daniel A. Barros \\ School of Engineering \\ University of Minho \\ 4800-058 Guimarães, \\ Portugal
}

\author{
Delfim F. Soares \\ CMEMS I\&D Centre \\ School of Engineering \\ University of Minho \\ 4800-058 Guimarães, \\ Portugal
}

\author{
José C. Teixeira \\ MEtRICs I\&D Centre \\ School of Engineering \\ University of Minho \\ 4800-058 Guimarães, \\ Portugal
}

\author{
Maria F. Cerqueira \\ Physic Center \\ School of Science \\ University of Minho \\ 4710-057 Braga, Portugal
}

\author{
Pauline Capela \\ School of Engineering \\ University of Minho \\ 4800-058 Guimarães, \\ Portugal
}

\author{
Senhorinha F. Teixeira \\ ALGORITMI I\&D Centre \\ School of Engineering \\ University of Minho \\ 4800-058 Guimarães, \\ Portugal \\ Macedo F. \\ Physic Centre \\ School of Science \\ University of Minho \\ 4710-057 Braga, Portugal
}

\begin{abstract}
A common failure mode of electronic printed circuit boards (PCB's) is the appearance of cold solder joints between the component and $\mathrm{PCB}$, during product life. This phenomenon is related to solder joint fatigue and is attributed mainly to the mismatch of the coefficients of thermal expansion (CTE) of component-solder-PCB assembly. With today's solder joint thickness decreasing and increasing working temperatures, among others, the stresses and strains due to temperature changes are growing, leading to limited fatigue life of the products. As fatigue life decreases with increasing plastic strain, creep occurrence should have significant impact, especially during thermal cycles and, thus, should be studied.

Through the cooling phase, on the production of PCB assembly's by the reflow technology, the hoven atmosphere temperature is adjusted in order to control the cooling rate. Narrow criteria is used so as to control the inter-metallic compounds (IMC) thickness, PCB assembly distortion and defects due to thermal shock. The cooling rate also affects solder microstructure, which has direct impact on creep behaviour and, thus, on the soldered joint reliability.

In this paper, a dynamic mechanical analyser (DMA) is used to study the influence of the solder cooling rate on its creep behaviour. SAC405 samples with two distinct cooling rates were produced: inside a hoven cooling and by water quenching. Creep tests were made on three-point-bending clamp configuration, isothermally at $25^{\circ} \mathrm{C}, 50{ }^{\circ} \mathrm{C}$ and $75^{\circ} \mathrm{C}$ and under three separate
\end{abstract}

levels of stress, 3, 5 and $9 \mathrm{MPa}$. The results show that creep behaviour has a noticeable cooling rate dependence. It was also noticed that creep propensity is exacerbated by the temperature at which stresses are applied, especially for the slower cooling rates. Creep mechanisms were related to the solder microstructural constituents, namely by the amount of phases ant their morphology.

Keywords:

SAC solder; microstructure; Creep; Solder reliability; Solder mechanical properties

\section{INTRODUCTION}

Although soldered joints may sometimes be used for purposes like heat conduction and dissipation in printed circuit boards (PCB's), the main target is to promote electrically connection of the various components and to provide mechanical integrity of those interconnections. For that reasons, the products reliability is directly correlated to the soldered joints quality [13]. With the growing concerns related to health and environmental hazards and the introduction of lead-free solders in industry, along with the increasing trend for shrinking electronics packaging, the development of highly reliable new lead-free solders has become an important area of interest [2-3]. Thus, the mechanical properties of the solders are currently one of the major concerns in electronic packaging industry. 
Ternary Sn-Ag-Cu (SAC) eutectic and nearly eutectic solders are among the best and most used lead-free solders in industry, basically because of their similar mechanical properties, wettability, and resistance to temperature cycling when compared to the old $\mathrm{Sn}-\mathrm{Pb}$ solders [4-7]. SAC solders, however, have higher thermal stress, thicker interfacial intermetallic compounds (IMCs) and, particularly, higher melting temperature [6]. The last imposes process production problems, at reflow soldering level, because some components are very sensible to the high temperatures required to melt solder and make a good interconnection and may overheat.

During electronic products service life, PCB's are subjected to a large number of causes that may lead to its failure. Some of them are impact [7], vibration [8] and thermal stresses [9]. Although two first ones may not be present or significant for all applications, the last is imposed in every PCB during its life, not only due to ambient temperature changes by also by components heating effect during service.

Because of the fact that PCB assemblies are made from numerous types of materials, i.e., epoxy based boards, Sn based solders, $\mathrm{Cu}$ pads, ceramic/other components, etc, there are present a large variety of thermal expansion coefficients (CTE). Due to that circumstance, a change in temperature, materials will expand or contract in different scales, creating shear stresses along various elements, especially on the soldered interconnections [10]. Actual miniaturizing trend of the assemblies [9] reduce the distance between component and board, exasperating this effect [11]. Continuous thermal cycling lead to repeating deformations that ultimately result in fatigue crack and failure [11].

During thermal cycling plastic deformation is apparently one of the major deformation mechanisms of solders. Creep deformation, a time-dependent plastic strain at constant stress and temperature, should also play an important role because the homologous temperature $(\mathrm{T} / \mathrm{Tm})$ of solders usually exceeds 0.6 $[1,12]$. Under that conditions the microstructure of the solder is unstable and creep and stress relaxation occur rapidly during the holding period at high temperature within each cycle. This suggests that creep in the soldered joints significantly impacts the thermo-mechanical reliability of the assembly joints [1, 1213].

During the reflow soldering process of PCB assemblies, both heating and cooling phases are executed at a controlled rate. The heating rate is controlled mainly due to the need to reduce thermal shock and to create temperature stages for the flux to clean the soldering surface and the solder to wet and react with the pads. The cooling rate is established according to the formation of an intermetallic layer which thickness must be controlled to guarantee a good soldering joint.

The transient cooling phase of each soldering joint is affected by a big number of factors, e.g., manufacturing parameters, local air speed and temperature, component density, thermal inertia of the component, thermal shading, etc. Thus, on the production of PCB's by reflow process, the cooling rate of an actual soldering joint can be very different, not only between different types of products, but also along the soldering joints of a specific board.
There is known that creep behavior has impact on the reliability of a soldered joint [14, 15]. Several studies refers cooling rate affects alloy microstructure and, in relation to them, its creep behavior [16-18]. In particular, Zequn et al. address creep and fatigue performance in relation to the cooling rate for eutectic $\mathrm{Pb}-\mathrm{Sn}$ solder and found steady state creep rate does not significantly change with the cooling rate, although fatigue life of fast cooled alloys was greater. Although its remarkable findings, the study focused on leaded solder alloys and not on SAC solders [18]. Ochoa et al. studied the effect of cooling rate on creep performance of bulk eutectic Sn-3.5Ag solder. He discovered that faster cooling rates increase the creep strength of the solder due to the refinement of the solder microstructure, were it was possible to find finer Sn-rich dendrites and finer $\mathrm{Ag}_{3} \mathrm{Sn}$ in the eutectic, providing more efficient obstacles for dislocation motion [19]. Although in this work was studied a lead free solder, the presence of copper in the alloy was not taken into account. Other authors studied the creep behavior of SAC solders with varying $\mathrm{Ag}$ and $\mathrm{Cu}$ composition, but not the influence of cooling rate on the microstructure and thus creep behavior [20]. Kanjilal et al. showed that stress and temperature have a significant effect on SAC alloys precipitates coarsening during creep, that promotes a change in the creep mechanism between low and high temperature [20]. The absence of knowledge about the influence of cooling rate on SAC solders microstructure, specifically the constituents volume fraction, and its effect on creep behavior, in particular for SAC405 solder for being a common use solder type on PCB assembly production by reflow, lead to the interest in this study. For that, SAC405 solder paste was melted and cooled at two different cooling rates, characterized in terms of microstructure morphology and constituents volume fraction and its creep behavior studied using a dynamic mechanical analyzer (DMA) device with varying stress and temperature.

\section{MATERIALS AND METHODS}

\section{Sample Preparation}

To produce the samples, it was used commercial F620 SAC405 solder paste, constituted by a $88 \mathrm{wt} \%$ colloidal suspension of type 3 (25-45 $\mu \mathrm{m}$ diameter) SAC405 (95,5\% Sn, $4,0 \% \mathrm{Ag}, 0,5 \% \mathrm{Cu}$ ) solder spheres on a rosin flux.

The melting of the solder was done by heating $75 \mathrm{~g}$ of solder paste, in an alumina crucible, to $300{ }^{\circ} \mathrm{C}$ during $20 \mathrm{~min}$. Simultaneously, a $16 \times 16 \times 35 \mathrm{~mm}^{3}(\mathrm{LxWxH}), 8 \mathrm{~mm}$ wall thickness, stainless steel mold was pre-heated on a hoven at 300 ${ }^{\circ} \mathrm{C}$. After that, the melted solder was poured into the stainless steel pre-heated mold and two cooling rates were employed: slow and fast. The slow cooling rate was obtained by placing the mold with the cooling solder back into the hoven, this time turned off. The fast cooling rate was achieved by quickly placing the mold with the cooling solder into water at ambient temperature. In both processes the temperature was registered using a $\mathrm{K}$ type thermocouple and a data logger and the result can be seen on Fig 1. 
From each block of solid solder produced, samples were cut to suitable size to test on the DMA $\left(\geq 25 \mathrm{x} \geq 3 \mathrm{x} 0.25 \mathrm{~W} \mathrm{~mm}^{3}\right.$ (LxWxT), with maximum deviance of $5 \%$ of nominal dimensions), using a stainless steel toothed saw disc cutter. Their shape is illustrated on Fig.2, both for solder blocks and final shaped sample.

After creep tests, a representative sort of samples was cut, mounted on an epoxy carrier, polished and chemical attacked in order to proceed to microscopic observations.

To characterize the material, hardness tests were made using a Shimadzu micro hardness tester type-M with $15 \mathrm{~s}$ indentation time and $100 \mathrm{~g}$ load. The results were obtained in HV test mode.
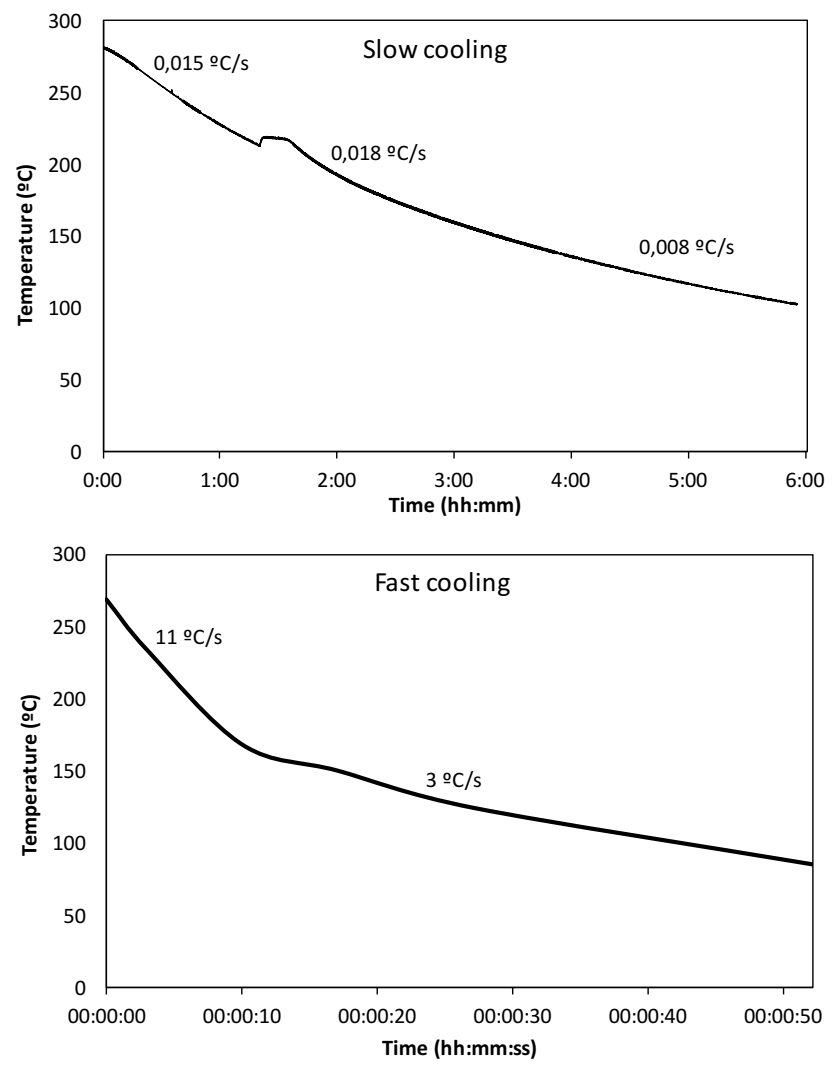

Fig. 1 - Temperature evolution of slow and fast cooled SAC405 samples
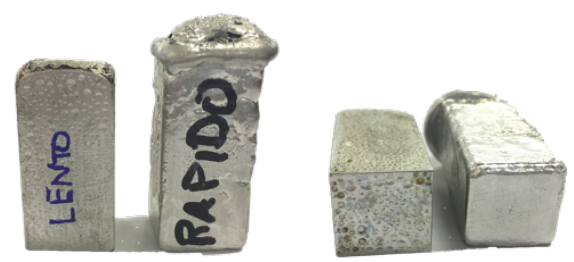

a)

b)

Fig. 2 - a) Slow (left) and fast (right) cooling rate solder blocks; b) sample machined and prepared to DMA creep tests

\section{Test Procedure}

The creep tests were performed on a TA Instruments Q800 DMA, using the $20 \mathrm{~mm}$ three-point-bending flexural clamp and creep-relaxation test mode procedure. In order to understand the effect of cooling rate on creep mechanism of the solder, samples were tested at three stress levels $(3,5$ and $9 \mathrm{MPa})$ for each cooling rate at three distinct as service life relevant temperatures (30, 50 and $\left.75^{\circ} \mathrm{C}\right)$. All this temperature levels represent homologous temperatures above half the melting temperature of the solder $\left(217^{\circ} \mathrm{C}\right.$, measured on a DSC/TGA), namely $0.62,0.66$ and 0.71 . As high temperature creep behavior tends to be more relevant at homologous temperatures above 0.6 [12-13], the selected testing temperatures are relevant for creep testing purposes.

The experimental routine comprised of an isothermal period of ten minutes before testing at the experiment target temperature, to ensure homogeneous temperature of the sample. Load and unload cycles were defined as 50 and 30 minutes, respectively, for each sample. Load and unload cycles were consecutively repeated four times. After the tests, steady-state creep rate was measured for each load cycle. A schematic representation of the test cycle and the strain rate measurement is illustrated on Fig. 3.

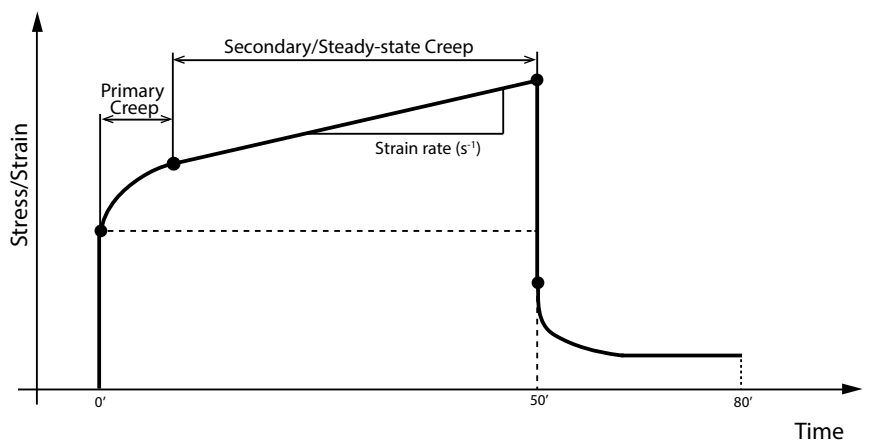

Fig. 3 - Schematic representation of creep tests performed on DMA

\section{RESULTS AND DISCUTION}

\section{Material Characterization}

In order to verify the chemical composition of the samples, it was randomly selected one from each cooling type lot, followed for chemical analysis by XRF spectrometry. The results are plotted on Table 1 and show that the as-cast concentration was guaranteed within acceptable limits. 
Table 1 - Chemical composition of samples (XRF analysis)

\begin{tabular}{lccc}
\hline & \multicolumn{3}{c}{ Element fraction $(\mathrm{wt} \%)$} \\
\cline { 2 - 4 } Sample & $\mathrm{Ag}$ & $\mathrm{Cu}$ & $\mathrm{Sn}$ \\
\hline Pure SAC405 & 4.10 & 0.72 & rest \\
\hline
\end{tabular}

The cooling speed effect on bulk SAC405 solder superficial hardness was investigated. As some samples rested, at least, $5 \mathrm{~h}$ at $50{ }^{\circ} \mathrm{C}$ or $75^{\circ} \mathrm{C}$, according to the test temperature, it was also investigated the effect of temperature aging on SAC405 hardness. Fig. 4 illustrates the results and reveal that cooling rate have a big impact on SAC405 hardness, increasing with the cooling speed. On the other side, the $5 \mathrm{~h}$ aging doesn't have a significant effect on the results, for both types of samples.

The microstructure is always an important feature when understanding mechanical behavior, and thus the creep performance, of metals and alloys. Because of that, optical and SEM microscopy observation was performed (Fig. 5). The constituents volume fraction, in each sample type, were measured by image analysis and are presented on table 2 . The results show an important occurrence: the change from a structure with a strong lamellar presence to a structure based essentially on coarse ( $\mathrm{Sn}$ ), when the cooling rate changes, respectively, from fast to slow rate. It is also possible to see the evidence that the slow cooled sample does not change its microstructural composition, $95 \%$ (Sn), when heated to as high as $75^{\circ} \mathrm{C}$ during $5 \mathrm{~h}$. This behavior may be basically related to the fact that the samples were able to reach a stable equilibrium when produced, due to the very slow cooling rate. On the other side, the fast cooled samples display kinetic behavior in terms of microstructure evolution with the exposition to temperatures below melting point. The results suggest that the (Sn) constituents grow when the sample is subjected to $5 \mathrm{~h}$ at temperatures as low as $50{ }^{\circ} \mathrm{C}$, phenomena that is accelerated by the temperature level. Dendritic volume fraction ( $\mathrm{Sn}$ based phase) increases during the stage at higher temperatures, which suggests that the microstructural composition of this samples, at the as-cast condition, are at an unstable equilibrium stage.

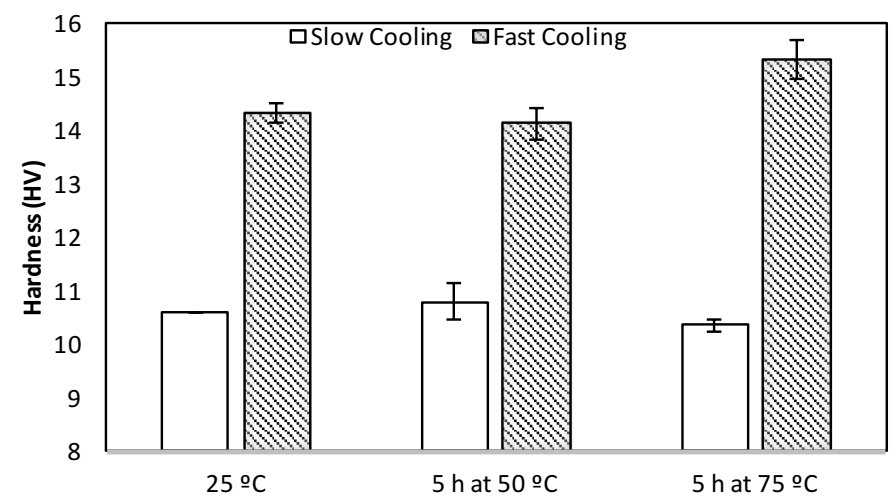

Fig. 4 - Surface hardness of fast and slow cooling rates for as casted and $5 \mathrm{~h}$ aged SAC405 solder

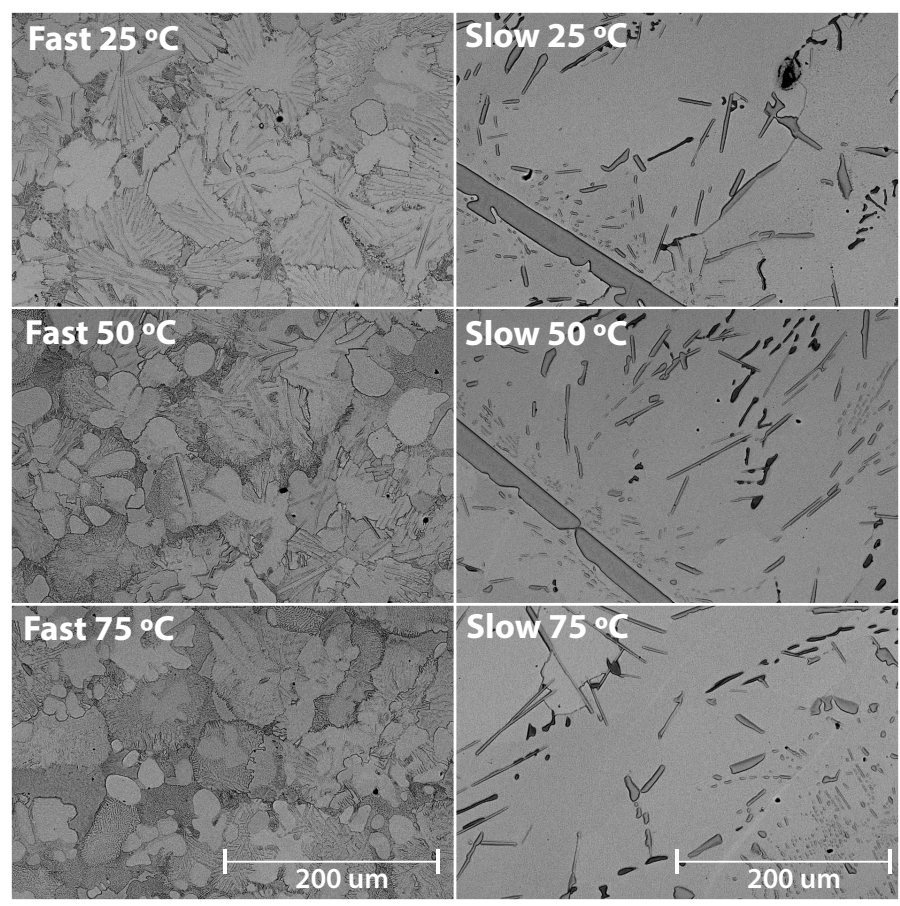

Fig. 5 - Microstructure observations for SAC405 with slow and fast cooling rate

Table 2 - Alloy constituents volume fraction (\%)

\begin{tabular}{llccc} 
& & \multicolumn{3}{c}{ Temperature $\left({ }^{\circ} \mathrm{C}\right)$} \\
& & 25 & 50 & 75 \\
\hline \multirow{2}{*}{ Slow } & $\%(\mathrm{Sn})$ & 95 & 95 & 95 \\
& $\%$ Others & 5 & 5 & 5 \\
\hline \multirow{2}{*}{ Fast } & $\%(\mathrm{Sn})$ & 22 & 37 & 38 \\
& $\%$ Others & 78 & 63 & 62 \\
\hline
\end{tabular}

\section{Creep Tests}

To evaluate the influence of cooling rate on creep properties of SAC405, creep curves of the specimens on this study were plotted on a creep strain - time chart. Fig. 6 presents an example of the obtained curves, for slow and fast cooled samples, tested at different temperatures $\left(25,50\right.$ and $\left.75^{\circ} \mathrm{C}\right)$ and at $5 \mathrm{MPa}$. It analysis allows to perceive, after an elastic instantaneous strain, the presence of a primary and secondary creep stages, as represented on Fig. 2. Primary creep stage is described as a transient high strain rate that decreases with time, mainly due to a phenomena known as work hardening. Secondary creep, or steady state creep, appears after primary creep, when strain rate reaches the minimum value. It is characterized by a constant strain rate along the time and is generally interpreted as an equilibrium between work hardening and dynamic or thermal recovery [21]. One difference that can be seen on the chart is the magnitude of the instantaneous elastic strain between the two types of samples. That value is related to the stiffness of the material and the conclusion is that the slow cooled samples are 
less stiff (lower Young modulus) than the fast cooled samples. The difference should be associated with the amount of the $(\mathrm{Sn})$ constituent on the alloy, which is much higher on slow cooled samples. Being metallic materials, as one could expect, the tests also reveals that the stiffness of SAC405, despite its cooling rate, decreases with the test temperature.

A plot of strain rate along the temperature, for all the sample types, was also done in order to study the effect of temperature on creep rate. This relationship is depicted on Fig. 7. Globally, it can be seen that creep rate increases with temperature, as expected, for fast and slow cooled samples. A more significant increase was obtained for the slow cooled samples at 50 and 75 ${ }^{\circ} \mathrm{C}$ and $9 \mathrm{MPa}$ of applied stress.
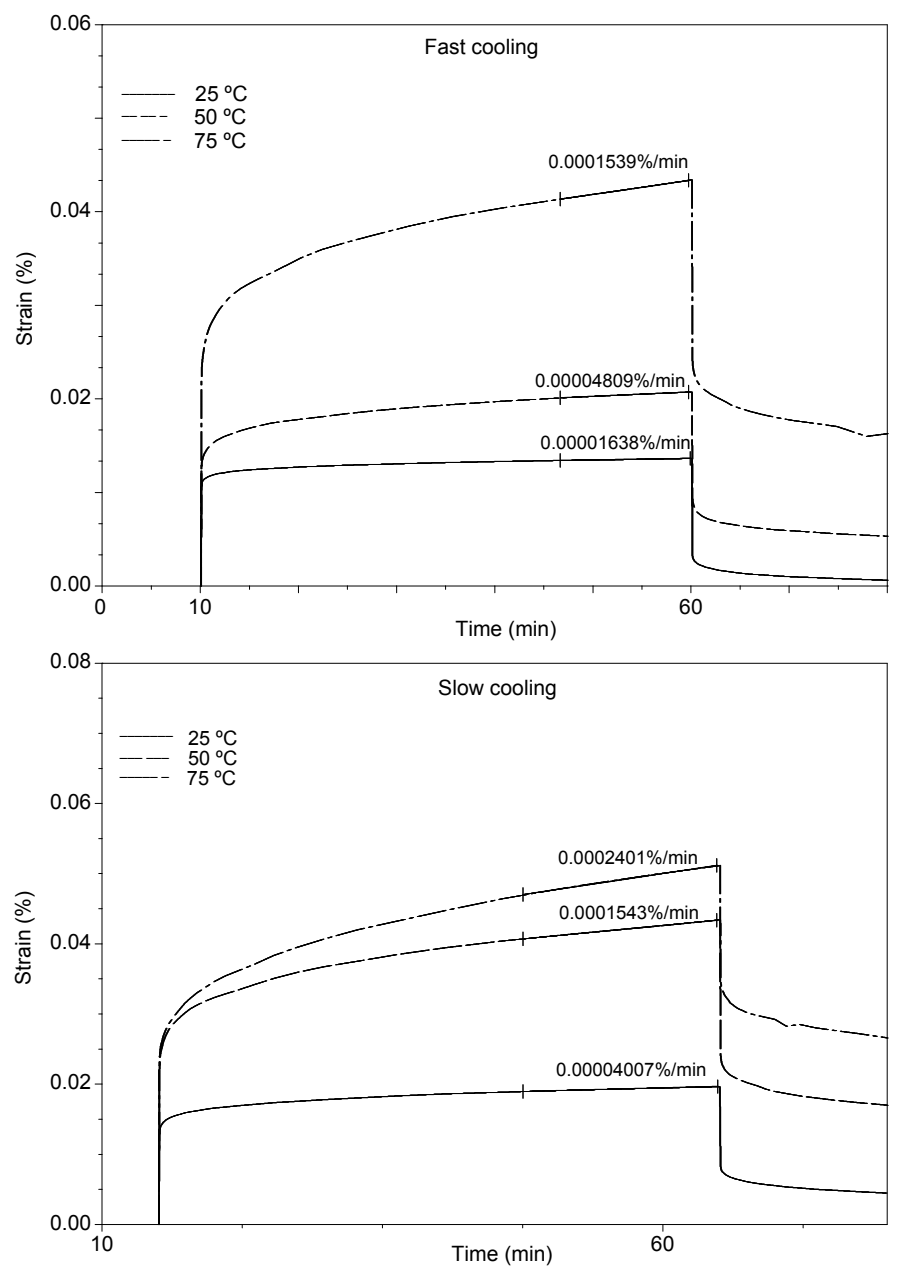

Fig. 6 - Strain rate during the creep tests, at $5 \mathrm{MPa}$, for slow and fast cooling SAC405 samples
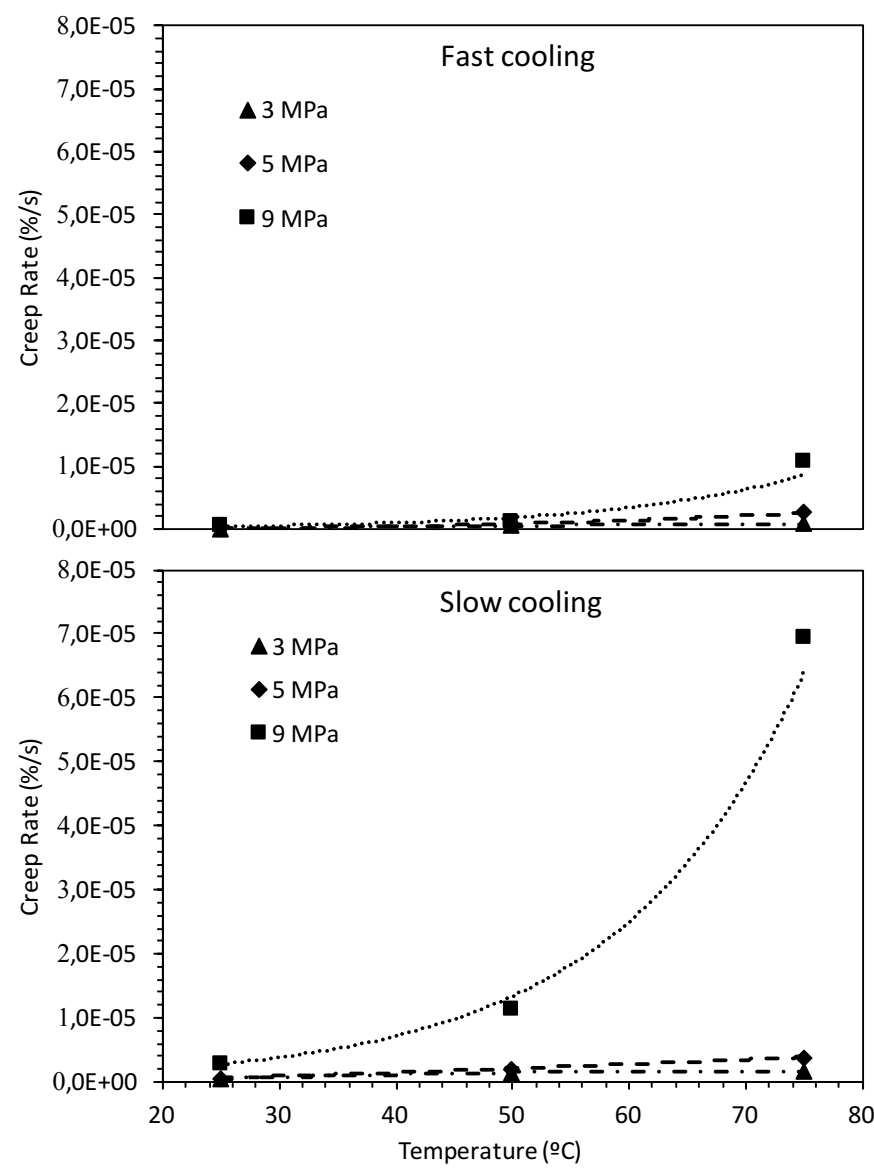

Fig. 7 - Effect of temperature on strain rate during the creep tests for slow and fast cooling SAC405 samples

Other obvious difference between the samples is the steady state creep rate. Because of that, its value was measured on the creep tests, and plotted on a creep rate - stress chart, for the three tested temperature levels: 25,50 and $75{ }^{\circ} \mathrm{C}$ (Fig. 8). It analysis allows to perceive that creep rate of the SAC405 is highly sensible to the alloy microstructure. On all tested temperatures, slow cooled SAC405 presents a higher creep rate. This behavior can be justifiable by the alloy microstructure, mainly constituted by the (Sn) phase on slow cooled samples (see Table 2).

As could be expected, due to the high homologous temperature of the tests, it was also observed that creep rate is very much sensible to the temperature, increasing with it for both slow and fast cooled samples. Creep strain is favored by the presence of the $(\mathrm{Sn})$ based microstructure, when compared with the lamellar type. This means that (Sn) phase has a higher susceptibility to creep than the lamellar constituents (predominant on the fast cooled alloy samples). 

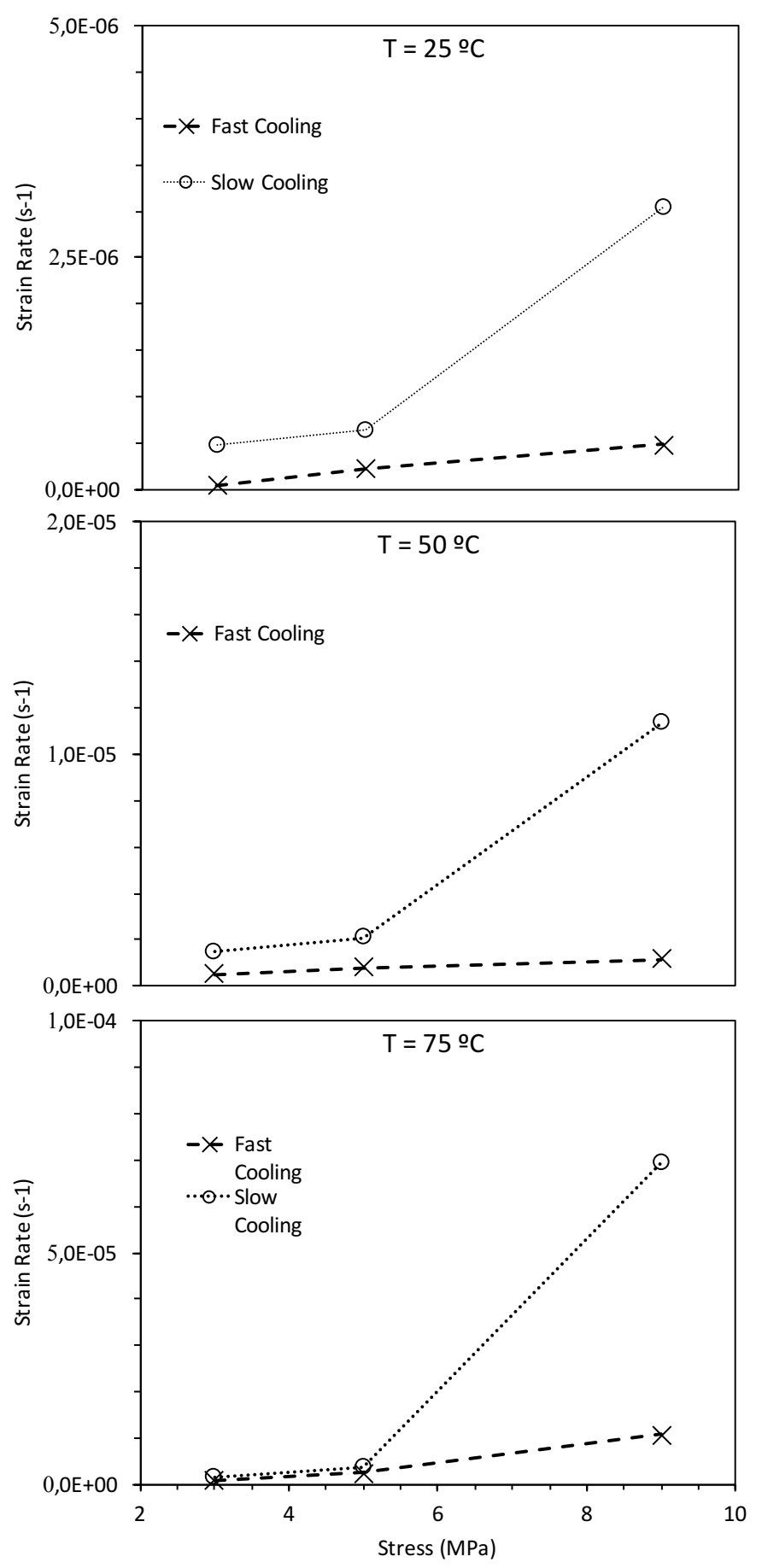

Fig. 8 - Creep rate of fast and slow cooled SAC405 bulk solder at $25^{\circ} \mathrm{C}, 50^{\circ} \mathrm{C}$ and $75^{\circ} \mathrm{C}$ along creep stress

In all the cases the creep rate increases with the applied stress. For fast cooled samples the increase in creep rate is almost linear with the applied stress, a behavior that is preserved with the temperature, up to $75^{\circ} \mathrm{C}$. The slow cooled samples, by its turn, with (Sn) based microstructure, have a different behavior. There's an exponential increase on the creep rate under stresses above $5 \mathrm{MPa}$, a phenomenon that is transverse to all the tested temperatures. This might indicate a change on the creep mechanism. Lee et al [22] indicate a creep deformation mechanism, for pure Sn, dominated by grain boundary sliding, rotating grains into the orientation that is most compatible with the applied stress irrespective of their mismatch with neighboring grains for low stress and low temperature conditions. For higher stress and/or temperatures the creep might be increasingly changed to a higher activation energy mechanism as the coarse-grained structure by bulk dislocation.

Creep activation energy can reasonably be estimated by a linear regression of steady-state strain rate along the reciprocal temperature, 1/T [23]. Its value is depicted on Fig. 9. It analysis reveal that calculated creep activation energy values are in accordance with the literature being a little inferior, insofar they're in the same order of magnitude for SAC solders Q [23, 24]. For fast cooled samples, creep activation energy does not seem to be significantly affected by the applied stress. On the other side, for slow cooled samples, activation energy is affected by the applied stress. It seems to exist a transition from a low energy creep mechanism, at low stress, to a high activation creep energy mechanisms, at higher stress, in accordance with literature $[17,22]$.

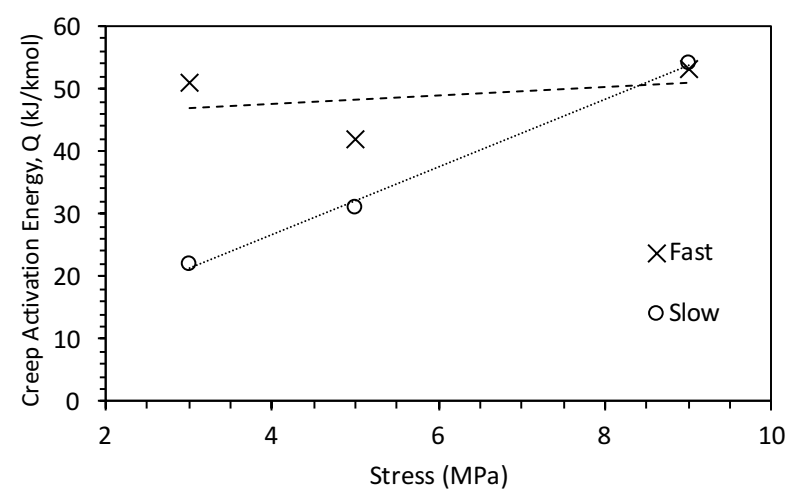

Fig. 9 - Creep activation energy for slow and fast
cooled samples

\section{CONCLUSIONS}

In this work the effect of microstructure of commercial SAC405 solder was studied in terms of creep behavior, giving particular attention to secondary creep rate. For creep purposes, the effect of temperature and stress were reviewed.

Cooling rate has major impact on microstructure of SAC405. Slow cooled SAC405 $\left(\sim 0,02{ }^{\circ} \mathrm{C} / \mathrm{s}\right)$ appears to have a predominant (Sn) constituent (up to $95 \%$ volume), being Ag and $\mathrm{Cu}$ elements grouped in form of needles. Fast cooled SAC405 $\left(\sim 10{ }^{\circ} \mathrm{C} / \mathrm{s}\right)$ present a smaller fraction, roughly $1 / 5$, of $(\mathrm{Sn})$ constituent and the rest in form of other constituents with lamellar shape ( $\mathrm{Ag}$ and $\mathrm{Cu}$ containing phases). This leads to differences in superficial hardness, being the fast cooled samples significantly harder than the slow cooled ones. It was also 
concluded that although slow cooled samples present a stable equilibrium microstructural state, fast cooled ones tend to evolve when subjected to temperature levels as low as $50^{\circ} \mathrm{C}$ for, at least, $5 \mathrm{~h}$. In those samples, $\mathrm{Sn}$ ) constituent volume fraction tends to increase.

Creep behavior was evaluated with temperature change. Results show that creep properties of alloys slow cooled have greater dependence on temperature. This behavior was attributed to alloy microstructure, mainly constituted by the (Sn) phase. On slow cooled samples a significant change on the creep behavior was observed, namely on the transition from 5 to $9 \mathrm{MPa}$. The calculated activation energy indicates that a change on the creep mechanism might occur for high temperatures and/or applied stress. For the fast cooled samples, a more linear behavior was observed with temperature and applied stress. Only for the higher stress, $9 \mathrm{MPa}$, a more pronounced creep rate was detected. This indicates that above mentioned changes associated with (Sn) phase creep behavior, with temperature and/or applied stress, are suppressed by the lamellar morphology.

\section{ACKNOWLEDGEMENTS}

The authors would like to express his acknowledgments for the support given by the Portugal Incentive System for Research and Technological Development. Project in co-promotion This research is sponsored by the Portugal Incentive System for Research and Technological Development.

This work is supported by: European Structural and Investment Funds in the FEDER component, through the Operational Competitiveness and Internationalization Programme (COMPETE 2020) [Project $\mathrm{n}^{\mathrm{o}}$ 002814; Funding Reference: POCI-01-0247-FEDER-002814]. This work was financed by FCT, under the Strategic Project UID/SEM/04077/2013; PEst2015-2020 with the reference UID/CEC/00319/2013 and UID/FIS/04650/2013.

\section{REFERENCES}

[1] Q. K. Zhang, Z. F. Zhang, In situ observations on creep fatigue fracture behavior of $\mathrm{Sn}-4 \mathrm{Ag} / \mathrm{Cu}$ solder joints. Acta Materialia 59 (2011), 6017-6028.

[2] A. K. Gain, Y. C. Chan, Growth mechanism of intermetallic compounds and damping properties of Sn$\mathrm{Ag}-\mathrm{Cu}-\mathrm{lwt} \% \quad$ nano- $\mathrm{ZrO}_{2} \quad$ composite solders, Microelectron Reliab (2014), 54:945-55.

[3] H. Emeka, N. D. Ekere, High temperature reliability of lead-free solder joints in a flip chip assembly, J Mater Process Technol (2012), 212:471-83.

[4] A. Wierzbicka-Miernik, et al, Corrosion behavior of lead-free SAC-type solder alloys in liquid media, Archives of Civil and Mechanical Engineering, (2015), Volume 15, Issue 1, Pages 206-213.

[5] B. Illésa, B. Horváth, Tin whisker growth from microalloyed SAC solders in corrosive climate, Journal of
Alloys and Compounds (2014). Volume 616, 15, Pages 116-121.

[6] A. T. Tana, A. W. Tana, F. Yusof, Evolution of microstructure and mechanical properties of $\mathrm{Cu} / \mathrm{SAC} 305 / \mathrm{Cu}$ solder joints under the influence of low ultrasonic power, Journal of Alloys and Compounds (2017), Volume 705, Pages 188-197.

[7] P. F. Fuchsa, G. Pintera, Z. Majorc, PCB drop test lifetime assessment based on simulations and cyclic bend tests, Microelectronics Reliability (2013), Volume 53, Issue 5, Pages 774-781.

[8] Y. Jianga, J.Y. Taoa, Y.A. Zhanga, G.J. Yunb, Fatigue life prediction model for accelerated testing of electronic components under non-Gaussian random vibration excitations, Microelectronics Reliability (2016), Volume 64, Pages 120-124 Proceedings of the 27th European Symposium on Reliability of Electron Devices, Failure Physics and Analysis.

[9] A. Sharma, Y. Jang, J. Kim, J. Jung, Thermal cycling, shear and insulating characteristics of epoxy embedded Sn-3.0Ag-0.5Cu (SAC305) solder paste for automotive applications, Journal of Alloys and Compounds (2017). Volume 704, Pages 795-803.

[10] L. Hana, A. Voloshina, I. Emrib, Study of the multilayer PCB CTEs by moiré interferometry, Optics and Lasers in Engineering (2004), Volume 42, Issue 6, Pages 613626.

[11] S. Ishikawaa, et al, Extending the fatigue life of Pb-free $S A C$ solder joints under thermal cycling. Microelectronics Reliability (2013), Volume 53, Issue 5, Pages 741-747.

[12] M. T. Zarmai, N. N. Ekere, C. F. Oduoza, E. H. Amalu, Evaluation of thermo-mechanical damage and fatigue life of solar cell solder interconnections, Robotics and Computer-Integrated Manufacturing (2016).

[13] J. W. Morris Jr. and H.L. Reynodls, Design and Reliability of Solders and Solder Interconnections, ed, Warrendale, PA: TMS, (1997), p. 49.

[14] R. G. Ross, Jr., A Systems Approach to Solder Joint Fatigue in Spacecraft Electronic Packaging, Journal of Electronic Packaging (1991), Vol. 113 / 121

[15] J. Liang, S. Downes, N. Dariavach, D. Shangguan, S. M. Heinrich, Effects of Load and Thermal Conditions on Pb-Free Solder Joint Reliability, Journal of Electronic Materials (2004), Vol. 33, No. 12

[16] J. K. Shang, Q. L. Zeng, L. Zhang, Mechanical fatigue of Sn-rich Pb-free solder alloys. Lead-Free Electronic Solders 211-227, 123, Springer Science and Business Media (2006)

[17] S. Mukherjee, M. Nuhi, A. Dasgupta, M. Modarres, Creep Constitutive Models Suitable for Solder Alloys in Electronic Assemblies, Journal of Electronic Packaging Vol. 138 / 030801-1 (2016). 
[18] M. Zequn \& Morris, J \& C. Shine, M \& S. E. Summers. Effects of cooling rate on mechanical properties of neareutectic tin-lead solder joints, Journal of Electronic Materials (1991). 20. 599-608.

[19] J F. Ochoa, X. Deng, N. Chawla, Effects of Cooling Rate on Creep Behavior of a Sn-3.5Ag Alloy, Journal of Electronic Materials (2004), Vol. 33, No. 12.

[20] A. Kanjilal, V. Jangid, P. Kumar, Critical evaluation of creep behavior of Sn-Ag-Cu solder alloys over wide range of temperatures, Materials Science \& Engineering A 703 (2017) 144-153.

[21] Boyer, E. Howard, Atlas of Creep and Stress-Rupture Curves, ASM International (1988).
[22] K. O. Lee, J.W. Morris JR., Fay Hua, Mechanisms of Creep Deformation in Pure Sn Solder Joints, Journal of Electronic Material (2013), Vol. 42, No. 3,.

[23] A. A. El-Daly, A. M. El-Taher, S. Gouda, Development of new multicomponent $\mathrm{Sn}-\mathrm{Ag}-\mathrm{Cu}-\mathrm{Bi}$ lead-free solders for low-cost commercial electronic assembly, Journal of Alloys and Compounds 627 (2015) 268-275.

[24] A. A. El-Daly, A. M. El-Taher, T. R. Dalloul, Enhanced ductility and mechanical strength of $\mathrm{Ni}$-doped $\mathrm{Sn}$ 3.0 Ag-0.5Cu lead-free solders, Materials \& Design (2014), Volume 55, Pages 309-318. 